\title{
The end of the Baltimore saga
}

One of the most corrosive disputes of recent years in the research community should be ended with the open acknowledgment of the error of an excess trust by the principal in the case.

DR David Baltimore, president of Rockefeller University in New York, has done the decent thing. In his statement on page 94 , he acknowledges that he was wrong to have defended the data of his colleague Dr Thereza Imanishi-Kari in the face of mounting doubts. He has also implicitly acknowledged that his truculence before the Dingell Committee two years ago was, to say the least of it, inappropriate; now he says that government has a legitimate right to inquire into the uses made of public money in research. Above all, he offers an apology to Dr Margot O'Toole, the postdoctoral fellow in Imanishi-Kari's laboratory who first became suspicious of the data published in 1986. That will not erase her painful experiences, but it is a handsome apology.

So what happens now? Has Baltimore said enough to bring an end to the process of inquiry that has consumed the past four years of many people's lives? There is some unfinished business, but one thing is clear: Baltimore has said enough to restore his own reputation as a fine scientist, a man of public spirit and a potentially superb and certainly imaginative president of an outstanding and distinctive research university. Some among his colleagues may be tempted to use this public acknowledgement of error by their leader as an excuse for furthering their own narrow causes, but they should instead reflect on what Baltimore's ingenuity may eventually accomplish for their institution. To make an error may reflect on a person's judgement, but to confess it in the circumstances in which Baltimore now finds himself is a mark of courage. He deserves a break.

\section{Opportunity}

Others will be less fortunate. The National Institutes of Health (NIH) have yet to say what will happen to ImanishiKari, against whom the charge of fabricating data had been laid. She is an able scientist, if a poor record keeper. What the Office of Scientific Integrity demonstrated last month is that data in a notebook submitted to the Dingell Committee had been cobbled together from different and irrelevant sources, but the status of the originally published data is still not clear. In one sense, it no longer matters, for the article concerned has been withdrawn. But both NIH and the Dingell Committee will want to know how this state of affairs arose. It is especially important that Imanishi-Kari should be given an opportunity to put her case. It is unlikely that this case would have been so prominent had it not been for the association with Baltimore.

The question will also arise of how an article now acknowl- edged to be unsound could have been published in a journal holding to rigorous standards of peer review. Baltimore himself says that his defence of his co-author was sustained by his "trust in the efficacy of the peer review process". But reviewers cannot tell whether data in an article submitted for publication are false except when there are internal inconsistencies or flagrant discrepancies with data already published elsewhere. Reviewers, rather, judge whether conclusions follow legitimately from the data offered in their support. In the disputed article, suggestive of an unexpected interaction between endogenous and transplanted genes in a mouse, the conclusions did not ring out with the clarity of a bell. The reviewers might well have asked that the work should have been confirmed before publication - and would probably have been scorned. It is therefore to be hoped that one outcome of this case will be a more proper recognition (especially in the Congress) of the limitations of peer review.

\section{Pitfalls}

So how can fraud be avoided in the future? Baltimore promises to "participate actively" in working out new guidelines for dealing with allegations of fraud and for protecting those who make them. Fine. But what can be done? This and other cases point to the importance of full and contemporaneous laboratory notebooks. More important still, they demonstrate the pitfalls for institutions that embark on investigations in the belief that allegations of misconduct are almost by definition unfounded. Whistleblowers have a lonely and thankless task which they are unlikely to take on lightly. Institutions have a duty to be more diligent than has usually been the case. They will thus safeguard not merely their own reputations, but also their independence. The mere existence of the Office of Scientific Integrity is a mark of how much they have lost already.

The incidence of misconduct also needs attention. By now there is ample evidence that the driving force lies in the competitive character of academic research, especially in the United States. People cut corners or even fabricate data sc as to simulate success and earn the rewards it brings - another grant, perhaps, or even a promotion. The same competitiveness has also made US biomedical research into the most successful scientific enterprise anywhere. The problem is how best to abate the evil consequences of competition without losing the benefits. That, more usefully than the development of further guidelines for the conduct of investigations, is the issue into which Baltimore should now put his energies. $\square$ 